\title{
21. Paradoxical Language in Chan Buddhism
}

\author{
Chien-hsing Ho
}

\section{I.}

Chinese Chan or Zen Buddhism is renowned for its improvisational, atypical, and perplexing use of words. In particular, the tradition's encounter dialogues, which took place between Chan masters and their interlocutors and are recorded in its koan ("public case") literature, abound in puzzling, astonishing, and paradoxical ways of speaking. In this chapter, we are concerned with Chan's use of paradoxical language. In philosophical parlance, a linguistic paradox comprises the confluence of opposite or incongruent concepts in a way that runs counter to our common sense and ordinary rational thinking. ${ }^{1}$ One naturally wonders about Chan masters' rationales for their use of paradox. There are also concerns about whether the use violates the logical law of noncontradiction to the effect that nothing can be both $\mathrm{P}$ and not-P all over in the same way at the same time.

Recently, Yasuo Deguchi, Jay Garfield, and Graham Priest have argued that certain Mahayana Buddhists are committed to the view that some contradictions are true, and that modern developments in paraconsistent logics show that such a view can be rational and acceptable. ${ }^{2}$ For example, some Buddhists describe certain things about an indescribable reality such that the indescribable is described. The reality is both

\footnotetext{
${ }^{1}$ There are at least two kinds of paradox: logical paradox and linguistic paradox. To see the contrast, Russell's paradox regarding Cantor's set theory is a logical paradox: the set of all sets that are not members of themselves contains itself as a member. In this chapter, we are solely concerned with linguistic paradox; also, in my usage, the paradoxical is not to be identified with the contradictory.

${ }^{2}$ These authors themselves endorse the philosophical position known as dialetheism, which holds that the law of noncontradiction fails, that some contradictions are true. For discussions on the law and the position, see Priest, Beall, and Armour-Garb 2004.
}

1

Chien-hsing Ho

Institute of Chinese Literature and Philosophy, Academia Sinica, Taiwan

Email: hochg@sinica.edu.tw 
Forthcoming in Dao Companion to Chinese Philosophy of Logic, Springer, 2019.

describable and not describable - a contradiction. On the view of these authors, the Buddhists take such contradictory statements to be true, which they say is rationally coherent and intelligible. ${ }^{3}$

However, Deguchi, Garfield, and Priest focus mainly on Indian Madhyamaka and Japanese Zen. It is doubtful that Chinese Chan masters and thinkers would affirm the truth of contradictory statements. In the Platform Sütra of the Sixth Patriarch, Huineng 惠能 (638-713 CE), the putative sixth patriarch of Chan Buddhism, is reported as saying that some people "slander [scriptural] teachings and say they make no use of words. As they say so, they should not even speak, for speech is a form of words." ${ }^{4}$ It is implied that the claim that one makes no use of words is self-contradictory and should not have been made in the first place. Nevertheless, this sutra's teaching of no-thought (wunian 無念) instructs one, paradoxically, to have no thought while engaged in thought. One would be both thinking and not thinking. We need to clarify this issue.

In any case, I intend in this chapter to investigate Chan masters' rationales for their use of paradox. My aim is also to show that Chan's paradoxical expressions are only seemingly contradictory and do not really violate the law of noncontradiction.

Chan became a viable Chinese Buddhist tradition during the Tang dynasty (618-907) and continued to develop for several centuries. The tradition produced a huge literature; consequently, our investigation of its use of paradox cannot but be limited and selective. It is now widely recognized among scholars of Chan studies that baffling encounter dialogues that appear in the sayings of Tang Chan masters are generally interpolations

\footnotetext{
3 Deguchi, Garfield, and Priest 2008: 399-401. For further related discussions, see Priest 2002 and Priest 2014. For Priest, the nature of reality is contradictory in the sense that it is such as to render certain contradictory statements true.

4 Yang 2001: 64. For this sutra, I rely chiefly on Yang 2001, which contains a well-collated text of a Dunhuang version that may date about $780 \mathrm{CE}$. In this chapter, all translations from traditional Chinese texts are mine.
} 
Forthcoming in Dao Companion to Chinese Philosophy of Logic, Springer, 2019.

made in the post-Tang era, whereas the masters' own sermons are more reasonable and bear more affinity with Mahayana scriptural teachings than the dialogues do. Thus, we need to distinguish the sermons from encounter dialogues. In the next (second) section, I first sketch key ideas of Chan that are pertinent to our investigation and then examine the use of paradox in the sermons associated with certain Tang masters of the Southern Chan. ${ }^{5}$ In the third section, I analyze the presence of paradoxical language in post-Tang encounter dialogues. The fourth section concludes.

\section{II.}

For Chan, the purpose of religious training is to realize or awaken to one's original mind (benxin 本心) or buddha-nature in order to free oneself from the samsaric cycle of life and death. I understand the notion of original mind as referring to our mind-heart in its limpid, nonabiding (wuzhu 無住), and unfettered state. In a sense we already live in original mind, though, being clouded by mental afflictions and habitual sedimentations of dualistic thinking, it is not consciously manifest to us. From the Chan perspective, original mind is all-inclusive and all-pervasive, just like empty space (xukong 虛空). As the pivotal experience of awakening is that of the mind being realized and becoming manifest, one would here experience a dynamic coalescing of one's mind and the myriad objects, which in the Platform Sütra is compared to a great sea that merges the waters of various streams into a whole. The subject-object duality is transcended and the awakened Chan practitioner may declare that the myriad things are present in their (original) mind.

\footnotetext{
5 A number of contemporary scholars have questioned the traditional opposition between "Northern School's gradual awakening" and "Southern School's sudden awakening." Yet, I shall not concern myself with this issue here. By "Southern Chan" I mean the lineages that were traditionally seen as belonging to the Southern School of Chan.
} 
Forthcoming in Dao Companion to Chinese Philosophy of Logic, Springer, 2019.

Since original mind is nonabiding, to realize it, an unawakened mind should learn to flow freely with the changes of thoughts and things without abiding in them or attaching itself thereto. Nonabidingness and nonattachment are valued highly in Chan, but care is needed here. One must not abide in, or attach oneself to, nonabidingness or nonattachment either. Significantly, for Chan, the myriad things are ever changing and devoid of any independent and substantial nature. They are then said to be empty. This, together with the above hinted nondual perspective, indicates that things are devoid of determinate natures and forms (xiang 相), intimately interrelated, and are not really distinct from each other. Thus, for instance, we must not see mountains definitively as mountains nor waters definitively as waters, and so forth. ${ }^{6}$ To cognize $\mathrm{X}$ definitively as $\mathrm{X}$ is to impose on it a fixed, determinate identity, which differentiates intrinsically $\mathrm{X}$ from non-X things and easily results in attachment to it.

Meanwhile, language provides us with an all-important access to the world around us and to other people, and Chan's attitude toward language is not as negative as scholars used to think. However, the use of nominal words tends to seduce one into reifying their referents, taking the latter to be substantial and distinctly demarcated entities, which may induce an attitude of attachment toward the referents. To note a way of countering this tendency, we may attend to the famous paradoxical formula in the Diamond Sütra to the effect that what is said to be $\mathrm{X}$ is not $\mathrm{X}$, and so is called $\mathrm{X}$. This sutra is highly influential in Chan and the formula presumably leads the Chan master Baizhang Huaihai 百丈懷海 (749-814) to claim that a teaching speech in Buddhism consists of three conjoined phrases such as "a bodhisattva, is not a bodhisattva, so is

\footnotetext{
${ }^{6}$ I am alluding to the celebrated Chan koan of seeing mountains as mountains; refer to footnote 28 for a related remark. See also the Essentials of the Transmission of Mind, in Taishō Shinshū Daizōkyō (abbreviated as T) 48: 381a15-18 (volume 48, page 381, column a, line 15-18), and the Discourse Records of Dazhu and Visiting Students from All Quarters, in Shinsan Dainihon Zokuzōkyō (abbreviated as $X$ ) 63: 25a23-b3.
} 
Forthcoming in Dao Companion to Chinese Philosophy of Logic, Springer, 2019.

called a bodhisattva" (henceforth, T1) and "dharma, not dharma, not not-dharma" (T2). ${ }^{7}$

The formula of the Diamond Sütra appears to state that something is both X and not$\mathrm{X}$ at the same time. ${ }^{8}$ Likewise, if we treat the term "bodhisattva" in $\mathrm{T} 1$ as a predicate, T1 would seem to involve the following logical form, which is a contradiction:

(1a) $(\forall y)[(y$ is bodhisattva $) \rightarrow(y$ is not bodhisattva $)]$

which is equivalent to:

(1b) $(\forall \mathrm{y})(\mathrm{By} \rightarrow \sim \mathrm{By})$

Yet, in light of Baizhang's related explication and Chan teaching in general, the formula can be unpacked as follows: that which is designated by the word " $\mathrm{X}$ " (which can be any nominal word) is not a determinate and substantial X, not definitively an X, and ought not be an object of attachment; if this is recognized, one can use " $\mathrm{X}$ " provisionally to refer to the designated item as X. Thus construed, the formula, far from implying any contradiction, nicely helps to eschew attachment to the word's referent while indicating the provisionality of the use of the word. Similarly, Baizhang's second phrase in T1 ("is not a bodhisattva") helps to eschew attachment to the referent of the first phrase ("a bodhisattva") as well as to empty the referent of determinacy and substantiality. Although other Chan masters may not employ the formula in its complete form, many negative expressions in Chan texts serve functions similar to that of the

7 Comprehensive Recorded Sayings of Master Baizhang, X 68: 8a10-12. Baizhang's explication, in X 68: $8 \mathrm{a} 13-15$, of the claim indicates that what is negated by the negative particle not is attachment to the referent of the negated phrase and any understanding that takes the referent to be definitively so and so.

8 In the beginning of their aforementioned paper, Deguchi, Garfield, and Priest (2008: 395-396) give a list of nine passages from Buddhist texts that they think contain contradictions. Three of the passages are cited from the Diamond Sütra and concern the application of the formula. 
Forthcoming in Dao Companion to Chinese Philosophy of Logic, Springer, 2019.

second phrase.

Baizhang's third phrase in T2 ("not not-dharma") can be construed as signifying the negation of a negation. The point is that one must not attach oneself to the negation expressed by the second phrase ("not dharma") nor take the latter to signify complete absence of the item negated by it. Now, the second and third phrases in T2 together represent a double negation of the form "neither X nor not-X," which negates both attachment to $\mathrm{X}$ and attachment to the negation of $\mathrm{X}$. Yet, it may be converted to the seemingly contradictory form "non-X and not non-X" or "X and not $\mathrm{X}$." Consider, for instance, the sentence "The Buddha is neither sacred nor profane." Here, "the Buddha" denotes an individual (say, "b"). If we view "neither sacred" as equivalent to "nonsacred," and then to "profane" (designated by "P"), we seem to be able to derive the following logical form, which is a contradiction:

(2a) $[(\mathrm{b}$ is $\mathrm{P}) \&(\mathrm{~b}$ is not $\mathrm{P})]$

which is equivalent to:

(2b) $[\mathrm{Pb} \& \sim \mathrm{Pb})]$

However, for Baizhang, to speak of the Buddha as neither sacred nor profane is not to affirm that the Buddha is non-sacred or non-profane. That is to say, the negation "not" in the sentence $\mathrm{S}$, " $\mathrm{x}$ is not-P," negates any substantial relation between $\mathrm{x}$ and $\mathrm{P}$ without predicating of $\mathrm{x}$ any property (say, non-P); $\mathrm{S}$ does not commit its utterer to accepting that $\mathrm{x}$ has any property. ${ }^{9}$ Consequently, the double negation "neither X nor not-X," as

9 Comprehensive Recorded Sayings of Master Baizhang, X 68: 8a15-16: “ “... the Buddha is just neither sacred nor profane. Do not wrongly say he is non-sacred and non-profane." We here allude to the distinction between two kinds of negation drawn by Indian and Chinese Mādhyamika thinkers. The negation in $\mathrm{S}$ is nonimplicative negation. By contrast, if the negation in $\mathrm{S}$ is implicative negation, then, while denying $\mathrm{P}$ of $\mathrm{x}, \mathrm{S}$ also implies the affirmation of some other property of $\mathrm{x}$ such that $\mathrm{S}$ commits 
Forthcoming in Dao Companion to Chinese Philosophy of Logic, Springer, 2019.

implied in Baizhang's conjoined phrases, would not for him entail any contradiction. Likewise, contrary to appearances, we cannot derive (2a) or (2b) from the sentence "The Buddha is neither sacred nor profane."

Indeed, even the sentence " $\mathrm{x}$ is $\mathrm{P}$ and not-P" would not be contradictory if the word "P" is ambiguous, or is used provisionally such that " $\mathrm{x}$ is $\mathrm{P}$ " connotes that $\mathrm{x}$ is not nonP. ${ }^{10}$ Chan expressions are typically provisional in the sense that they do not predicate of their referents determinate properties, but are used expediently for immediate purposes and are to be negated especially when one becomes attached to their referents or takes the latter to be definitively such and such. In particular, the parity between T1 and $\mathrm{T} 2$ suggests that, for Baizhang, even when the third phrase is stated in an affirmative way (as in T1), the affirmation expressed may actually be a provisional affirmation that should be construed as the negation of a negation (as in T2). In this vein, "is P" in the sentence " $\mathrm{x}$ is $\mathrm{P}$ and not-P" would not predicate the property $\mathrm{P}$ of $\mathrm{x}$, but rather express the negation of the negation of $\mathrm{P}$, namely, not not-P (or, not non-P). As a result, the sentence would not imply the contradiction that P belongs and does not belong at the same time to $\mathrm{x}$.

Moreover, for Chan, Buddhist teachings are, like medicines, remedial in nature. Language is used not so much for its cognitive function of expressing factual descriptions of the world as for its noncognitive function of fulfilling therapeutic, heuristic and evocative purposes. For example, as Baizhang comments, a Buddhist

its utterer to acceptance of that property in $\mathrm{x}$.

10 The Chinese Mādhyamika thinker Sengzhao (374?-414 CE) is quite influential in Chan. On his view, the provisional use of the word "existent" with respect to the thing $\mathrm{x}$ is intended to show that $\mathrm{x}$ is not nonexistent, whereas that of the word "nonexistent" is to show that $\mathrm{x}$ is not existent. The words function by negatively differentiating $\mathrm{x}$ from what $\mathrm{x}$ is not, rather than positively characterizing $\mathrm{x}$ as definitively existent or nonexistent. See the Treatise of Sengzhao, T45: 152c12-14, 159b11. Although Chan masters may not have stated similar ideas explicitly, their recognition of the provisionality of language may well point in the same direction. See also the following remark on Baizhang. 
Forthcoming in Dao Companion to Chinese Philosophy of Logic, Springer, 2019.

teacher may sometimes teach that "There is Buddha," some other times that "There is no Buddha," depending on the audience's intellectual illness. ${ }^{11}$ The teacher may teach "There is Buddha" in order to remove the audience's doubt about the existence of buddha-nature, but may teach "There is no Buddha" to quell one's attachment to buddha-nature. What matters is the effectiveness of the teachings in achieving their purposes, but not their truth, concerning which alone the issue of contradiction occurs. Given the above discussion, we can now look at a few instances of paradox in Tang dynasty Chan. Let us attend to the Platform Sütra teaching of no-thought first. Clearly, this sutra opposes the extinction of thought. It states that the purpose of the negation implied in the term "no-thought" is to negate one's attachment to the objects of thought and free oneself from afflictions that arise from dualistic ideas. It is suggested that one whose thought arises directly from original mind, presumably one who has awakened to the mind, knows best how to think without attachment to the objects. ${ }^{12}$ Then, the word "thought" in the aforementioned "to have no thought while engaged in thought" is ambiguous: its first occurrence signifies a thought of attachment while the second occurrence does not. Since the word is used in two different senses, there is no contradiction to the effect that one is thinking and not thinking in the same respect at the same time.

Some of the paradoxical expressions in Tang Chan are not unusual in Chinese Buddhism. For example, the Chan master Shenhui 神會 (684-758) claims that

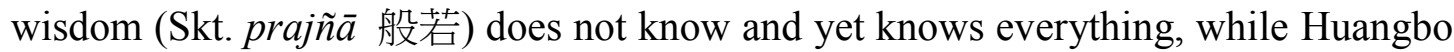

\footnotetext{
${ }^{11}$ For the provisionality of language and its remedial character, see the Comprehensive Recorded Sayings of Master Baizhang, X 68: 7c21-24, 12c14-19, and the Essentials of the Transmission of Mind, T 48: 382c27-383a02. Wang (2003: 179) writes: "For the Chan masters and students, if the therapeutic functions of these paradoxical expressions are effective, there are no contradictory meanings at all within the pragmatic context."

12 Yang 2001: 19-20, 37-38. See Ho 2016 for relevant discussion.
} 
Forthcoming in Dao Companion to Chinese Philosophy of Logic, Springer, 2019.

Xiyun 黃檗希運 (751?-850?) states that the Buddha speaks all day without having spoken. ${ }^{13}$ Both sayings may come from Sengzhao's Treatise of Sengzhao and could be said to be rooted in certain Mahayana scriptures. ${ }^{14}$

For Huangbo, original mind is all-inclusive, capable of pervading the myriad things, which are held to be empty. This results in a nondualistic ontology, in which the mind is nondual with the myriad things and there is no genuine hindrance or demarcation between the things. In consequence, the mind is nondual with language, which is among the things pervaded by it. Given that silence can be taken to symbolize the ineffable original mind, speech and silence are nondual as well. ${ }^{15}$ Thus, the Buddha's speaking is not really distinct from his silence or not speaking.

Herein, the paradoxicality of Huangbo's statement is due not so much to the ambiguity of the words used as to Chan's nondualistic ontology, in which are embedded the notions of original mind and emptiness. Although this may imply the nonduality of $\mathrm{P}$ (speaking) and not-P (not-speaking), this nonduality is not a strict or logical identity and so we cannot derive a contradiction from it. As a metaphorical illustration, consider the case of foam on the sea surface. The foam is not strictly identical with the sea water around, yet is existentially part of, and not distinct from, the water. The relation between

13 Yang 1996: 26 (Cf. Treatise on the Essential Gate of Entering the Way through Sudden Awakening, $X$ 63: 18b24-c4); Wanling Record of Chan Master Huangbo Duanji, X 68: 21c17-18. Shenhui does not give reasons for his claim. Probably, wisdom does not know because it does not know its object through a mind of attachment and dualistic discrimination; wisdom knows everything because it knows original mind, which comprises all things within itself.

14 Treatise of Sengzhao, T 45: 153a27-29, 153c26. For a recent exposition of Sengzhao's use of paradoxical expression, see Ho 2013.

15 Wanling Record of Chan Master Huangbo Duanji, X 68: 21c13-14: "Speech is silence, silence is speech, so speech and silence are nondual." Since, in Chan Buddhism, original mind is generally taken to be ineffable, the question arises as to whether Chan thinkers fall into the contradiction of describing the indescribable. I have, in Ho 2015, attempted to show how one can express the ineffable without contradiction. Then, this issue may not pose a serious problem to Chan. 
Forthcoming in Dao Companion to Chinese Philosophy of Logic, Springer, 2019.

speech and original mind (or the fusional unity of myriad objects and the mind) may be understood by analogy with the foam and sea water. In any case, Huangbo's statement that the Buddha speaks all day without having spoken is not contradictory.

Similarly, appealing to the all-inclusiveness of original mind and the emptiness of all things as a basis, Huangbo claims, paradoxically, that life-and-death and nirvana are not distinct but form a unity. ${ }^{16}$ Indeed, because he appears to identify nirvana with original mind, Huangbo can readily take nirvana to be nondual with life-and-death while being aware of their differences in certain respects. Incidentally, within this conceptual framework, the best practice for a Chan practitioner would paradoxically be to practice nothing. Or, as Huangbo makes clear, the practitioner simply needs to learn how not to seek for, and attach oneself to, anything. As noted above, the goal of Chan training is to realize or awaken to one's original mind. Since we already live in the mind, to seek for, and so objectify, it would only counteract its realization; similarly, to attach oneself to the myriad objects would only cloud its manifestation. When one truly refrains from seeking for, and attaching oneself to, original mind and the myriad objects, then and only then may one become awakened to the mind.

Often, Chan's paradoxical expression resembles the combination of Baizhang's first two phrases (as "A Bodhisattva is not a Bodhisattva") and is intended to quell the audience's attachment to the linguistic referent and indicate the latter's emptiness, indeterminacy, or illusoriness. For example, Huangbo teaches that "mind is not mind," "form is not form," "existence is not existence," "dharma is non-dharma, non-dharma

${ }^{16}$ Essentials of the Transmission of Mind, T 48: 381a2-29; Wanling Record of Chan Master Huangbo Duanji, X 68: 20b1-8. Recall that a linguistic paradox comprises the confluence of incongruent concepts. Since "life-and-death" and "nirvana" are incongruent concepts, we have a paradoxical expression here. Incidentally, the equation of life-and-death with nirvana is a recurrent theme in Chan and Chinese Buddhism. 
Forthcoming in Dao Companion to Chinese Philosophy of Logic, Springer, 2019.

is dharma," and so forth. ${ }^{17}$ These expressions are uttered to indicate that the referents of such words as "mind," "form," "existence," and "dharma" are empty, illusory, and unobtainable. The audience is thereby advised that one must not be attached to any of them.

Many paradoxical expressions in Chan sermons of Tang dynasty concern the notion of mind. Dazhu Huihai 大珠慧海, a pupil of the illustrious Chan master Mazu Daoyi 馬祖道一 (709-788), affirms, quoting an unnamed patriarch, that only by realizing that mind is not mind can one truly understand mind and its various functions. Further, Huangbo instructs that "this mind is the mind of no-mind," that "mind is itself mindless, and there is no mindless one either." 18 It would seem that one both has and does not have mind.

The thrust here, I think, is that, for Chan, our mind is really void of any cognizable form and is ungraspable and unobtainable. In its true nature, the mind is none other than the all-inclusive original mind. Yet, we fail to cognize its true nature and tend to conceive of it as, say, an inner mental entity confined within the body. Such a conception is to be negated. Then, what is negated by Huangbo's "no-mind" and "mindless" is this internally confined and seemingly identifiable mind, a mind that is constructed while in a state of delusion. As there should not be any attachment to the idea of no-mind, it is added that there is no mindless one either. Meanwhile, this emphasis on no-mind has a practical significance. As one empties one's mind, not

17 Wanling Record of Chan Master Huangbo Duanji, X 68: 20a4-24.

18 Discourse Records of Dazhu and Visiting Students from All Quarters, X 63: 29b18; Essentials of the Transmission of Mind, T 48: 380b1-2, b12-13. The notion of no-mind is a common theme in Chan Buddhism. The Treatise on No Mind (無心論), a Chan text probably composed in the Tang dynasty, states paradoxically that though one has no mind, one can very well see, hear, feel, and know, that genuine mind is none other than no-mind. The text makes it clear that we are said to have no mind because our mind is really formless and so unobtainable, and that what is negated by "no-mind" is the mind of delusive thought. See App 1995: 35-64. 
Forthcoming in Dao Companion to Chinese Philosophy of Logic, Springer, 2019.

treating it as something inwardly locatable, one may rather expand the mind outwards. This may help one to realize eventually what one's mind really is, namely, the allinclusive original mind.

The above discussions suggest that paradoxical expressions in Chan texts of Tang dynasty are not truly contradictory. Obviously, there are reasons for using such expressions. In the Chan context, their use may help to indicate the nonsubstantial and indeterminate nature of the referent of the word used and help one to refrain from attaching oneself to the referent. It also helps to show the provisional and remedial characters of language. In addition, their use flows naturally from Chan's nondualistic ontology, in which are embedded the notions of original mind and emptiness. On the other hand, paradoxical language may serve the functions of dislodging the interlocutor's habitual way of thinking and of evoking in them an experience of awakening. This is most likely the case in Chan's encounter dialogues, to which we now turn.

\section{III.}

An encounter dialogue in Chan Buddhism takes place between a Chan master and an interlocutor (a pupil, a monk, or a layperson) or interlocutors. ${ }^{19}$ Such dialogues take many linguistic forms and may involve shouting, silence, gesture, and such physical acts as hitting and kicking. They are similar in that the master's words (and gestures) typically transgress upon our commonly shared sense of things and dislodge the interlocutor's expectation and habitual way of thinking. In most cases, the words are not strictly paradoxical. They are simply perplexing or, in many cases, seemingly

\footnotetext{
19 An encounter dialogue may occur between two Chan masters, especially when one master is assessing the other's attainment of awakening, but I shall generally disregard this type of encounter dialogue.
} 
Forthcoming in Dao Companion to Chinese Philosophy of Logic, Springer, 2019.

irrelevant to the interlocutor's question.

For instance, a question most often asked in an encounter dialogue is, "What was the first patriarch's intention in coming from the West?" To this question, Chan masters give, among others, these answers: "The cypress tree in the yard;" "To wash this old monk's feet;" "To walk in the day and lay down at night;" "There is no intention in coming from the West;" "I'll tell you once the stone turtle understands human speech." The answers are puzzling, if not nonsensical. Meanwhile, to the question "Two dragons vie for a pearl, which one gains it?" Chan masters' answers include: "Where is the pearl?;" "The gainer loses it;" "Gain is loss;" "The one with claws and teeth does not gain it;" "The pearl is everywhere on the ground but looks like mud to the eyes." Some of the answers are indeed paradoxical, while some others are at most at variance with the background assumptions. Although our focus should be on paradoxical expressions, much of the following discussion applies to encounter dialogue in general.

We begin with an illuminating encounter dialogue that was traditionally believed to take place between Bodhidharma (470?-543?) and Huike 慧可 (487-593), the first and second patriarchs of Chan Buddhism: ${ }^{20}$

Huike: "I have no peace of my mind. Teacher, please pacify it for me."

Bodhidharma: "Bring forth your mind, and I will pacify it for you."

Huike: "I seek for it but the mind is unobtainable."

Bodhidharma: "There! I have pacified your mind."

20 Jingde Record of the Transmission of the Lamp, T51:219b21-23. Given the popularity of this dialogue in post-Tang Chan Buddhism, even though it plausibly did not occur between the two patriarchs, we can reasonably regard it as an encounter dialogue, which may well have occurred between some Chan practitioners. For convenience sake, I write as if it took place between the patriarchs. 
Forthcoming in Dao Companion to Chinese Philosophy of Logic, Springer, 2019.

Notably, Huike's reply to the effect that his mind is unobtainable does not show that he has realized the true nature of his mind and Bodhidharma would be pleased to give him his sanction. In the present context, it does not require a Chan-like awakening realization for one to take one's mind to be unobtainable: after all, we are unable to bring forth our mind (or physical heart where the mind may be thought to be located) to someone else. What is really perplexing is that Bodhidharma then claims to have pacified Huike's mind when he seems to have done nothing at all. He claims, somewhat paradoxically, to have pacified Huike's unobtainable and so seemingly unpacifiable mind.

In order to bring into relief Huike's and Bodhidharma's different understandings of the unobtainability of mind, let us consider these two statements: ${ }^{21}$

(A) This mind is unobtainable.

(B) This unobtainable is the mind.

In his reply, Huike basically expresses statement (A), which can be simply a description of the empirical fact that one cannot bring forward one's mind to others. However, it may be the case that Huike actually has a deeper understanding of his mind than merely grasping the fact; that is, he rightly cognizes that, in its true nature, the mind is formless and unobtainable. Even so, Huike does not truly realize this unobtainable mind as such. With (A), indeed, one may tend to take the subject term "this mind" to designate something inside within one's body. One may tend to delimit and reify the referent of the term and conceive of it as an inner object or substance, a property of which is

21 The following elucidation draws some ideas from Abe 1985: 11-14, though Abe's interpretation of the dialogue differs from what is proposed here. 
Forthcoming in Dao Companion to Chinese Philosophy of Logic, Springer, 2019.

revealed by the predicate "unobtainable." Even though the mind is disclosed to be unobtainable or bear the property of unobtainability, it remains an inner entity that is distinct from things outside. Plainly, no Chan master will sanction this understanding of the mind. ${ }^{22}$

On the other hand, in claiming to have pacified Huike's mind, Bodhidharma induces him to realize that what he is taking to be unobtainable is none other than his genuine, originally limpid and peaceful mind. Bodhidharma's response is tantamount to expressing statement (B). Since the subject of (B) is primarily a negative adjective, one is less likely to project something out there or in here and delimit its existence. The word "unobtainable" may generate a sense of oddity and puzzlement. Yet, it may draw an earnest Chan practitioner's mind to a state of emptiness wherein conceptual delimitation and grasping is quiescent, indeed a state of the dynamic fusion of the mind and the myriad objects. Such a state can present itself in an infinite number of ways. In the present context, it is expressed by the predicate "the mind." As "the mind" is merely a predicate, instead of delimiting and reifying its referent, one may see it as indicating a way in which the state presents itself. Now, if one truly realizes the unobtainable state of emptiness, which presents itself as one's genuine mind, one surely will experience peace of mind. Upon hearing his teacher's claim, we are told, Huike immediately attains awakening while realizing that his mind resides neither inside nor outside, nor in the middle, and yet is everywhere. ${ }^{23}$ The mind to which Huike is awakened is a mind of no-mind.

Although statement (B) is somewhat bizarre, it serves the purposes of evading

\footnotetext{
${ }^{22}$ It is not meant that this understanding is always present whenever one expresses (A). The tendency may be blocked if the language user recognizes the provisionality of the words used. In normal cases, a Chan master would prefer (A) to (B) simply because (A) accords better with people's conventional way of using language.

${ }^{23}$ Recorded Sayings of Master Fenyang Wude, T 47: 604a19-20.
} 
Forthcoming in Dao Companion to Chinese Philosophy of Logic, Springer, 2019.

conceptual delimitation and reification of one's mind and of drawing the mind to an unobtainable state of emptiness. In a sense, (B) is a miniature of Chan encounter dialogues, which more or less serve the two functions: (i) to dislodge the interlocutor's habitual way of thinking, and (ii), given appropriate conditions, to transform and open up the interlocutor's mind so as to evoke in it an experience of awakening. Let us discuss the two functions in some detail.

Chan tradition distinguishes live words (huoju 活句) from dead words (siju 死句) and recommends the use of the former. According to the Chan master Dongshan Shouchu 洞山守初 (910-990), if there are words within words, the (latter) words are dead words; if there are no words within words, the words are live words. ${ }^{24}$ Basically, dead words are those that induce the listener to stick to their literal meaning and evaluate and react to the words in light of the commonly held sense of things, which may generate further explanatory words. By contrast, live words are words that are seemingly nonsensical and run counter to our habitual way of thinking, which induces the listener to disregard their literal meaning and semantic function of representing things in the world. (Further effects of live words are explained below.) Clearly, paradox is a good candidate for the use of live words. When used in an encounter dialogue, such paradoxical expressions as "The gainer loses it," "A rootless tree grows on a rock," and "One rides a water buffalo while walking on foot" may render the interlocutor at a loss to make sense of their representational content. Since the expressions are not meant to be representational in function, none of them is contradictory in the sense of representing mutually contradicting states of affairs.

\footnotetext{
24 Recorded Sayings of Ancient Worthies, X 68: 248a10. Cf. Wright 1992: 133. The linguistic form, paradoxical or otherwise, of the words used may not itself determine whether the words count as live words. We might also need to take into account the context of using the words as well as the understanding of the listener.
} 
Forthcoming in Dao Companion to Chinese Philosophy of Logic, Springer, 2019.

In this context, consider for comparison an oft-used Chan method for dislodging one's habitual way of thinking: the master holds up, or points at, something, say, a stick, and says to the interlocutor, "Don't call it a stick, but tell me what it is. Quick! Quick!" Hearing such words, the interlocutor may be at a loss, deprived of their customary way of using words to designate things. Here the order "Don't call it a stick" precludes one from following one's (most) habitual way of objectifying and identifying the stick. ${ }^{25}$ Similarly, in Chan's use of paradoxical expression, the paradoxical sense conveyed by the expression prevents one from following one's habitual way of taking the expression to represent the way things are.

While paradoxical expressions in encounter dialogue are not representational, some of them may be intended to lead the interlocutor beyond their literal meaning to approximate the import that the master intends to convey but may have difficulty putting into words. For instance, the expression "The gainer loses it" may, apart from its dislodging function, also be meant to indicate that one's original mind (the pearl!) is not to be realized by conceptual delimitation and grasping, which import may as well be indicated by the expression "The one with claws and teeth does not gain it." Here we may understand indication as an indirect mode of expression: an indication indirectly expresses and makes known its indicated import or referent, which, for some reasons, cannot be properly described or represented by words. (The notion of indication draws on the famous Buddhist simile of a finger pointing to the moon: the finger points toward, or indicates, the moon but in no way represents it.) Indeed, many expressions, paradoxical or otherwise, in encounter dialogue are partially indicative and what they indicate concern chiefly the ineffable original mind or the aforesaid state of

\footnotetext{
25 Of course, one can think for another word to identify the object. Yet, such thinking may instantly arouse the master's shouting or hitting.
} 
Forthcoming in Dao Companion to Chinese Philosophy of Logic, Springer, 2019.

emptiness. ${ }^{26}$ In any case, the key point for us is that, when construed indicatively, such expressions as "The gainer loses it" do not involve any contradiction.

The dislodging function of an encounter dialogue is only preliminary; it paves the way for the other function, which is to transform and open up the interlocutor's mind so as to evoke in it an experience of awakening in which one realizes the dynamic fusion between one's mind and the myriad objects. Here it must be said beforehand that, for those of us, myself included, who have never had any experience of what it is like to attain Chan awakening, it is difficult to understand how the dialogue or its live words can have such a transformative or evocative force. Consequently, my explanation cannot but be brief and conjectural.

Common people tend to take their mind to be an inner entity that is distinct from external objects. They also take a stick to be an external object distinct from the mind. The customary use of such distinct words as "mind" and "stick" to designate their referents reinforces the latter's delimitation. Now, a dialogue that embodies statement (B) may help to prevent one from internalizing the mind and demarcating it from its objects. The above Chan method may help to prevent one from externalizing the stick and demarcating it from the mind. In particular, Chan's emphasis on no-mind, the emptiness of all things, and nonattachment, as well as an encounter dialogue's dislodging function, may play a role here. All these, together with proper meditation practice, may help a practitioner, on hearing the master's live words, to overturn the cognitive chasm between the mind and its objects such that they come to experience a dynamic subject-object fusion. One is then awakened to one's original mind, which pervades all things yet abides in none. Of course, some live words are paradoxical in

\footnotetext{
${ }^{26}$ An indication is broadly cognitive as it is meant to refer indirectly to, and intimate something about, a reality while denying any correspondence between it and the reality. By "partially" is here meant that a Chan expression can be both indicative and remedial or evocative.
} 
Forthcoming in Dao Companion to Chinese Philosophy of Logic, Springer, 2019.

form.

When a Chan master's utterance functions to transform the interlocutor's mind and evoke therein an experience of awakening, we may say that the master performs a perlocutionary speech act that produces in the interlocutor's mind a specific mental effect. ${ }^{27}$ That is, apart from conveying its literal meaning and, possibly, indicated import, the utterance also brings about the effect of transforming the interlocutor's mind such that they come to experience that which previously transcends their experience. Here, the expression uttered may be said to be evocative in function as it is intended to call forth the awakening experience of realizing one's original mind and seeing the world in a refreshingly nondual way. Evocation is a noncognitive, nonreferential mode of expression, so it is inadequate to speak of truth, falsity, and contradictoriness in respect of evocative sentences. One can only speak of efficacy and inefficacy in respect of them.

The arising of an awakening experience requires that one abandon one's deep-rooted cognitive habit of demarcating one's mind from its objects. When the experience arises, the fundamental subject-object boundary collapses, and the awakened practitioner finds it hard to fit the new experience into our ordinary conceptual grids. As the boundary collapses, all things become paradoxically both one and many, same and different. ${ }^{28}$ It

\footnotetext{
27 See Fung 2008: 236-242. Fung's ideas draw on Davidson 1978. I do not find convincing Davidson's view that a metaphor carries no message other than its literal meaning. However, I agree with Fung that a Chan master's utterance can produce a perlocutionary effect on the interlocutor's mind.

28 Remarking on the renowned Chan discourse about seeing mountains as mountains and seeing mountains not as mountains, Abe (1985: 18) writes: "Thus in the Zen Awakening attained by Wei-hsin, on the one hand, mountains are really mountains in themselves, waters are really waters in themselves - that is, everything in the world is real in itself; and yet, on the other hand, there is no hindrance between any one thing and any other thing - everything is equal, interchangeable, and interfusing. Thus we may say: 'Mountains are waters, waters are mountains.' It is here in this Awakening ... that Zen says, 'A bridge flows, whereas water does not flow' ..."
} 
Forthcoming in Dao Companion to Chinese Philosophy of Logic, Springer, 2019.

is then natural for the awakened to resort to paradoxical expressions to express their awakening experience or whatever is considered ultimate in Chan. The expressions may also indicate figuratively their indirect referents' linguistic indeterminability. Consider, for example, the following dialogues:

Question: "What is the truth of reality?"

Answer: "A rootless tree grows on a rock."

Question: "The myriad things return to one. Where does the one return to?"

Answer: "One faces south to see the Northern Dipper."

Question: "What is it like for one to come to life from within death?"

Answer: "One is not allowed to walk in night but must arrive at dawn."

Significantly, here we cannot conclude that Chan masters take certain contradictory expressions to be true, and that, for them, the nature of reality is contradictory in the sense that it is such as to render those expressions true. The paradoxicality of the masters' words is due largely to the content of the awakening experience, which is impossible for language to adequately categorize and determine. Insofar as one, in undergoing the experience, feels a strong sense of oneness with an object, it makes sense to say oneself and the object are the same. Insofar as one's body and the object are different in experienced form and location, it is also correct to say oneself and the object are not the same. Since the two sayings draw on different perspectives, they do not together violate the law of noncontradiction to the effect that nothing can be both $\mathrm{P}$ and not-P in the same way at the same time. In addition, for Chan, the linguistic indeterminability concerned betokens the deficiency of language and thought in 
Forthcoming in Dao Companion to Chinese Philosophy of Logic, Springer, 2019.

capturing the way things really are. By contrast, the view that certain contradictory expressions of reality are true appears to assign to reality a determinate, albeit contradictory, nature that can be precisely captured by language.

Before ending this section, we may briefly mention yet another dimension of Chan's use of language. In numerous cases, a Chan master's utterance arises instantly and spontaneously from their experience of the immediate situation around them. For instance, a master was once asked about the first patriarch's intention in coming from the West, as he was washing his feet, he then answered, "To wash this old monk's feet." In cases like this, it is futile to look for any hidden message. This helps to explain why in many cases the master's words in encounter dialogue seem irrelevant to the interlocutor's question. ${ }^{29}$

In this section, we have discussed several key linguistic functions and dimensions of Chan encounter dialogues. The master's words as live words are not representational in function: they are not meant to represent the way things are. Then, even if a master says in an encounter dialogue that " $\mathrm{x}$ is $\mathrm{P}$ and not-P," the master is very unlikely to affirm the expression as true in the sense of truly representing reality. In some cases, the expression uttered, paradoxical or otherwise, is evocative, yet it is inadequate to speak of contradictoriness in respect of evocative expressions. In some other cases, the expression is indicative in function, and this recognition, as we saw above, may conduce to resolving literal contradiction.

IV.

In this chapter, we have investigated the presence of paradoxical language in Chinese

${ }^{29}$ Cheng (1973) proposed two principles to explain the significance and logical dissolvability of Chan puzzles and paradoxes: the principle of ontic non-commitment and the principle of contextual demonstration. Some of my ideas in this section may resemble the two principles. 
Forthcoming in Dao Companion to Chinese Philosophy of Logic, Springer, 2019.

Chan Buddhism, explored the rationales for the use of paradox, and discussed whether Chan masters would affirm the truth of contradictory statements. As Chan is a long tradition that consists of various sects, lineages, texts and individuals, there remains much work to be done in this regard. However, our study has suggested that, in Tang Chan masters' sermons and post-Tang encounter dialogues in general, the use of paradox does not violate the logical law of noncontradiction to the effect that nothing can be both $\mathrm{P}$ and not-P in the same way at the same time.

As mentioned at the beginning of the chapter, Deguchi, Garfield, and Priest focus mainly on Indian Madhyamaka and Japanese Zen in their argument for the thesis that certain Mahayana Buddhists are committed to the view that some contradictions are true. Given that Japanese Zen developed out of Chinese Chan, let us consider a passage from the Zen master Dōgen (1200-1253) that they cite in support of their thesis: ${ }^{30}$

Just understand that birth-and-death is itself nirvana. There is nothing such as birth and death to be avoided. There is nothing such as nirvana to be sought. Only when you realise this are you free from birth and death.

The last sentence of this passage hints at the general Buddhist view that to attain nirvana is to be free from life and death (birth-and-death), which in turn entails that nirvana and life and death are different. Yet, the first sentence states to the effect that nirvana and life and death are not different. In addition, the passage seems to imply contradictorily that there both is and is not nirvana.

Now, we saw above that Huangbo, on account of the all-inclusiveness of original

\footnotetext{
${ }^{30}$ Deguchi, Garfield, and Priest 2008: 396. I shall only discuss this passage from the Chinese Chan perspective.
} 
Forthcoming in Dao Companion to Chinese Philosophy of Logic, Springer, 2019.

mind and the mind's sameness with nirvana, claims that life-and-death and nirvana are the same. He can readily claim them to be different on the ground that nirvana alone, but not life and death, entails genuine realization of original mind as well as freedom from life and death. These two claims are made from different perspectives. Meanwhile, the emptiness of all things indicates that there is no nirvana to be sought, though this does not mean the latter's nonexistence. In addition, to seek for nirvana qua original mind is to conceptually objectify the mind, which is least effective for the realization of nirvana. Thus, there is no nirvana to be sought yet there is nirvana to be realized. It should be evident from this analysis that, for Chan, the above passage does not involve any real contradiction.

Many factors, we have seen, contribute to Chan's characteristic paradoxical way of speaking, and we must not be led by the surface grammar of expressions into supposing the presence of contradiction therein. As we consider language's abundant wealth of meaning and the various ways in which words can be used, we may refrain from making the supposition and learn to appreciate Chan's atypical but skillful use of language. ${ }^{31}$

\section{References}

Abe, Masao. 1985. Zen and Western Thought, edited by William R. LaFleur. Honolulu: University of Hawai'i Press. (Its first chapter brilliantly and thoughtfully elucidates the well-known Chan koan of seeing mountains as mountains.)

App, Urs. 1995. “Mushinron-Tonkō shutsudo no ichi tekisuto”無心論：敦煌出土 の一テキスト.Zenbunka Kenkyūjo kiyō 21 (May): 1-69. (Containing an English translation of the Treatise on No Mind, a Chan text probably composed in the Tang

\footnotetext{
31 The author thanks Professor FUNG Yiu-ming and an anonymous reviewer for their very valuable comments and suggestions on earlier drafts of this chapter.
} 
Forthcoming in Dao Companion to Chinese Philosophy of Logic, Springer, 2019.

dynasty.)

Cheng, Chung-ying. 1973. “On Zen (Ch'an) Language and Zen Paradoxes.” In Journal of Chinese Philosophy 1.1: 77-102. (An early but significant essay on Chan's use of paradoxical language.)

Compendium of Five Lamps 五燈會元, edited by Puji 普濟, X, vol. 80, no. 1565.

Comprehensive Recorded Sayings of Master Baizhang 百丈廣錄. Compiled in the Recorded Sayings of Ancient Worthies, X 68: 6a11-14a7. (A record of the sermons of the Chan master Baizhang Huaihai.)

Davidson, Donald. 1978. "What Metaphors Mean." In Sheldon Sacks, ed., On Metaphor. Chicago: University of Chicago Press.

Deguchi, Yasuo, Jay L. Garfield, and Graham Priest. 2008. “The Way of the Dialetheist: Contradictions in Buddhism." In Philosophy East and West 58.3: 395-402. (Arguing that certain Mahayana Buddhists, including the Zen master Dōgen, are committed to the view that some contradictions are true.)

Discourse Records of Dazhu and Visiting Students from All Quarters 諸方門人參問 語錄. By Dazhu Huihai. X, vol. 63, no. 1224. (A record of the sayings of the Chan master Dazhu Huihai.)

Essentials of the Transmission of Mind 黃檗山斷際禪師傳心法要, edited by PEI Xiu 裴休, $T$, vol. 48, no. 2012A. (A well-known record of the sayings of the Chan master Huangbo Duanji.)

Fung, Yiu-ming. 2008. "How to Do Zen (Chan) with Words? An Approach of Speech Act Theory." In Mou Bo, ed., Searle's Philosophy and Chinese Philosophy: Constructive Engagement: 229-242. Leiden: Brill. (A philosophical analysis of the functions of Chan koan from the perspective of speech act theory.)

Ho, Chien-hsing. 2013. "Ontic Indeterminacy and Paradoxical Language: A Philosophical Analysis of Sengzhao's Linguistic Thought.” In Dao: A Journal of 
Forthcoming in Dao Companion to Chinese Philosophy of Logic, Springer, 2019.

Comparative Philosophy 12.4: 505-522. (An analysis of Sengzhao's use and understanding of paradoxical language.)

2015. "Resolving the Ineffability Paradox." In Arindam Chakrabarti and

Ralph Weber, eds., Comparative Philosophy without Borders. London:

Bloomsbury Academic.

---------. 2016. "Interdependence and Nonduality: On the Linguistic Strategy of the Platform Sūtra." In Philosophy East and West 66.4: 1231-1250. (A rational analysis and reconstruction of the main linguistic strategy taught in the Platform Sutra.)

Jingde Record of the Transmission of the Lamp 景德傳燈錄, edited by Daoyuan 道 原, $T$, vol. 51, no. 2076.

Priest, Graham. 2002. Beyond the Limits of Thought. Oxford: Oxford University Press. 2014. "Speaking of the Ineffable ..." In LIU JeeLoo and Douglas L. Berger, eds., Nothingness in Asian Philosophy. New York: Routledge.

Priest, Graham, J. C. Beall, and Bradley Armour-Garb, eds., 2004. The Law of NonContradiction: New Philosophical Essays. Oxford: Oxford University Press.

Recorded Sayings of Ancient Worthies 古尊宿語錄, edited by Yicangzhu 覧藏主, $X$, vol. 68 , no. 1315 .

Recorded Sayings of Master Fenyang Wude 汾陽無德禪師語錄, edited by Chuyuan 楚圓, $T$, vol. 47, no. 1992.

Shinsan Dainihon Zokuzōkyō 凹新纂大日本續藏經 (abbreviated as X). In CBETA Chinese Electronic Tripitaka Version April 2014. Taipei: Chinese Buddhist Electronic Text Association.

Taishō Shinshū Daizōkyō 大正新脩大藏經 (abbreviated as T). In CBETA Chinese Electronic Tripitaka Version April 2014. Taipei: Chinese Buddhist Electronic Text Association. 
Forthcoming in Dao Companion to Chinese Philosophy of Logic, Springer, 2019.

Treatise of Sengzhao 肇論. By Sengzhao. T, vol. 45, no. 1858. (A collection of important essays written by the Chinese Mādhyamika thinker Sengzhao.)

Treatise on the Essential Gate of Entering the Way through Sudden Awakening 頓悟入 道要門論. Attributed to Dazhu Huihai. $X$, vol. 63, no. 1223. (This text probably records the discourses of Dazhu's preceptor, Daozhi 道智, who belonged to Shenhui's lineage.)

Wang, Youru. 2003. Linguistic Strategies in Daoist Zhuangzi and Chan Buddhism: The Other Way of Speaking. London and New York: RoutledgeCurzon. (A rich and thoughtful work that deals with the linguistic strategies of Chan Buddhism as well as Daoist Zhuangzi.)

Wanling Record of Chan Master Huangbo Duanji 黃檗斷際禪師宛陵錄. Compiled in the Recorded Sayings of Ancient Worthies, X 68: 16b20-23a6. (A record of the sayings of the Chan master Huangbo Duanji.)

Wright, Dale S. 1992. "Rethinking Transcendence: The Role of Language in Zen Experience." In Philosophy East and West 42.1: 113-138.

Yang, Zengwen 楊曾文, ed., 1996. The Record of the Chan Discourses of the Monk Shenhui 神會和尚禪話錄. Beijing: Zhonghua Shuju. ed., 2001. The Platform Sutra of the Sixth Patriarch: A New Recension Based on the Manuscripts from Dunhuang 新版敦煌新本六祖壇經. Beijing: Zongjiao Wenhua Chubanshe. (A recommendable, well-collated edition of the Platform Sutra of the Sixth Patriarch.) 